\title{
A Jmportância dos Estudos de Crenças e Atitudes para a Sociolinguística
}

The Importance of Studies of Beliefs And Attitudes to Sociolinguistics Jacqueline Ortelan Maia BOTASSINI*

Resumo: Estudos relacionados ao tema "Crenças e Atitudes Linguísticas" têm apontado pistas para a Sociolinguística na compreensão de questões que podem estar relacionadas a determinadas atitudes linguísticas manifestadas por um grupo ou por uma comunidade de fala. Em toda sociedade, as diferenças de "poder" existentes entre grupos sociais distintos podem ser percebidas na variação linguística e nas atitudes para com essas variações. Normalmente, os padrões de uso da linguagem do grupo dominante são referenciados como o modelo necessário à ascensão social; já o uso de linguagem, dialeto ou sotaque de baixo prestígio reduz as oportunidades de sucesso na sociedade. Pesquisas sobre Crenças e Atitudes Linguísticas podem ampliar a discussão sobre os fatores de mudanças linguísticas, sobre a influência no aprendizado de segundas línguas, sobre as questões de prestígio e desprestígio - que levam ao preconceito não só em relação à língua que o outro fala, mas também em relação à comunidade desses falantes. Assim, este trabalho abordará itens importantes para a compreensão da referida temática, a saber: a) conceitos de crença e de atitude; b) componentes, formação/ desenvolvimento e modificação das atitudes; c) conceitos como estigma, preconceito, prestígio/status linguístico, identidade linguística, lealdade e deslealdade linguística.

Palavras-chave: Crenças. Atitudes. Sociolinguística.

* Doutorado em Estudos da Linguagem, na Universidade Estadual de Londrina (2013). Docente da Universidade Estadual de Maringá (UEM) desde 1997. Contato: jombotassini@uem.br. 
Abstract: Studies related to the theme "Linguistics Beliefs and Attitudes" have shown paths to Sociolinguistics to understand issues that may be related to certain linguistic attitudes manifested by a group or by a speaking community. In the whole society, the differences of "power" existent among distinct social groups may be realized through the linguistic variation and through attitudes towards these variations. Normally, the standards of language use of the dominant group are referred to as necessary models to social mobility, however the use of dialects or low profile accent reduces the opportunities of being successful. Researches on linguistic beliefs and attitudes may broaden the discussion about the factors of linguistic changes, about the influence on a second language learning process, about issues of prestige or discredit - which lead to prejudice not only regarding the language the other speaks, but also regarding these speakers community. Thus, this work approaches important items to understand the theme: a) concepts of belief and of attitude; b) attitudes components, formation/development and modification; c) concepts like stigma, prejudice, linguistic prestige/status, linguistic identity, linguistic loyalty and disloyalty.

Keywords: Beliefs. Attitudes. Sociolinguistics.

\section{Introdução}

Não é recente o interesse da Sociolinguística pelos estudos de Crenças e Atitudes Linguísticas. No trabalho de Labov (2008) sobre a mudança fonética ocorrida no inglês falado na ilha de Martha's Vineyard, já se verificou a importância desses fatores.

Estudos relacionados a esse tema têm apontado pistas para a Sociolinguística na compreensão de questões que podem estar relacionadas a determinadas atitudes linguísticas manifestadas por um grupo ou por uma comunidade de fala. Também possibilitam "predizer" um dado comportamento linguístico.

Giles, Ryan e Sebastian (1982) ressaltam que, em toda sociedade, as diferenças de "poder" existentes entre grupos sociais distintos podem ser percebidas na variação linguística e nas atitudes para com essas variações. 
Normalmente, os padrões de uso da linguagem do grupo dominante são referenciados como o modelo necessário para a ascensão social; já o uso de linguagem, dialeto ou sotaque de baixo prestígio, pelos membros de grupos minoritários, reduz as oportunidades de sucesso na sociedade.

Moreno Fernández (1998) informa que, em 1970, Agueyisi e Fishman já chamavam a atenção para a importância que os estudos de atitudes têm no campo da Sociolinguística. Por meio desses estudos, é possível

... conhecer mais profundamente assuntos como a eleição de uma língua em sociedades multilíngues, a inteligibilidade, o planejamento linguístico, o ensino de línguas; além disso, as atitudes influem decisivamente nos processos de variação e mudança linguísticos que se produzem nas comunidades de fala. Uma atitude favorável ou positiva pode fazer que uma mudança linguística se cumpra mais rapidamente, que em certos contextos predomine o uso de uma língua em detrimento de outra, que o ensino-aprendizagem de uma língua estrangeira seja mais eficaz, que certas variantes linguísticas se confinem aos contextos menos formais e outras predominem nos estilos cuidadosos. Uma atitude desfavorável ou negativa pode levar ao abandono e ao esquecimento de uma língua ou impedir a difusão de uma variante ou uma mudança linguística. (MORENO FERNÁNDEZ, 1998, p. 179, tradução nossa).

Para a Sociolinguística, de acordo com López Morales (2004), o principal problema está em determinar até que ponto a atitude expressa por um indivíduo está simplesmente relacionada a fenômenos linguísticos específicos ou em que medida ela é, na verdade, uma atitude de valorização aos usuários de determinado grupo social.

O autor salienta, ainda, que as crenças e as atitudes podem afetar os fenômenos específicos de um idioma, as variedades diatópicas ou diastráticas de alguns deles ou a língua em sua totalidade e as línguas maternas e estrangeiras que vivam ou não em uma mesma comunidade de fala, isto é, as línguas em contato. Para ele, suas consequências são variadas, mas a mais grave é o estímulo à discriminação linguística. 


\section{Crenças e Atitudes Linguísticas}

Importa destacar que, ao consultar trabalhos de Sociolinguística e de Crenças e Atitudes (tanto sociais quanto linguísticas) ${ }^{1}$ a fim de apresentar uma conceituação que este estudo julgasse adequada para definir os termos "crenças" e "atitudes", deparou-se com o problema de as pesquisas voltadas para essas áreas pouco se debruçarem, especificamente, a definir "crença". Por outro lado, encontram-se várias reflexões sobre o termo "atitude". $\mathrm{Na}$ verdade, crenças e atitudes aparecem, nesses trabalhos, estreitamente imbricadas, de modo que falar de uma sem se referir à outra se torna muito difícil. Isso ocorre sobretudo porque a maior parte dos trabalhos que trata desse assunto baseia-se na concepção mentalista, não separando crença de atitude, ou melhor, compreendendo crenças como um componente das atitudes. Este trabalho, entretanto, comungará com as ideias de López Morales (2004) sobre o tema e, assim como o referido autor, separará o conceito de crença do conceito de atitude.

Assim, optou-se por, inicialmente, apresentar esses termos separados, na tentativa de elaborar uma definição mais restrita de cada um deles. Para tanto, este trabalho aproveitará, muitas vezes, referências da área da Linguística Aplicada, que, ao contrário da Sociolinguística e dos estudos sobre Crenças e Atitudes, apropria-se bastante do termo crenças e bem menos do termo atitude. Evidentemente, serão aproveitadas as referências "gerais" e não as que se reportam especificamente à temática do ensino-aprendizagem.

\subsection{Crenças}

Diversas são as áreas do conhecimento que recorrem à temática das crenças para o desenvolvimento de seus trabalhos: Filosofia, Teologia, História,

\footnotetext{
${ }^{1} \mathrm{O}$ interesse a respeito do tema Crenças e Atitudes Linguísticas surgiu com os psicólogos sociais. Assim, as definições para esses termos estão voltadas, inicialmente, para a perspectiva social, para as crenças e as atitudes referentes a um objeto social. $\mathrm{O}$ objeto social, entretanto, pode ser teoria, situação, acontecimento, língua, dialeto, grupo, pessoa, etc. Então, ao interessar-se por um objeto social, pode-se estar interessado em uma língua ou dialeto específico. Assim, falar em objeto social pressupõe falar, dentre outras coisas, a respeito da língua. E aquilo que se refere à atitude social pode ser usado para referir-se à atitude linguística.
} 
Psicologia, Educação, Sociologia, Linguística, Sociolinguística, dentre outras. Disso resulta ser muito complexo definir "crenças", já que cada área possui um objeto de estudo diferente ou, ao menos, parcialmente diferente. Assim, são muitos os termos, os conceitos, as definições, os sentidos atribuídos para referirem-se a elas.

Nos dicionários de língua portuguesa, registram-se, com mais frequência, as seguintes definições: ato ou efeito de crer; fé religiosa; convicção íntima; opinião formada; crendice; superstição; forma de assentimento que se dá às verdades de fé, que é objetivamente insuficiente, embora subjetivamente se imponha com grande convicção; estado, processo mental ou atitude de quem acredita em pessoa ou coisa; disposição subjetiva a considerar algo certo ou verdadeiro por força do hábito ou das impressões sensíveis (NASCENTES, 1981; BORBA, 2004; FERREIRA, 2009; HOUAISS, 2009).

Silva, A. (2005), em estudo sobre crenças voltado para a área da Linguística Aplicada, ratifica essa complexidade e exibe um quadro resumindo as diferentes definições atribuídas ao termo crenças, apresentando um breve histórico que vai desde o conceito conferido a crenças pelo filósofo Peirce (1877) até estudos contemporâneos, como os da linguista Barcelos (2004), conforme segue:

... ideias que se alojam na mente das pessoas, como hábitos, costumes, tradições, maneiras folclóricas e populares de pensar. (PEIRCE, 1877 apud SILVA, A., 2005, p. 67).

... não são somente um conceito cognitivo, mas também social, porque nascem de nossas experiências e problemas, de nossa interação com o contexto e da nossa capacidade de refletir e pensar sobre o que nos cerca. (BARCELOS, 2004 apud SILVA, A., 2005, p. 69).

Em pesquisa posterior, Silva, A. (2011) ainda ressalta a dificuldade em definir "crenças" e, apoiando-se em Pajares (1992), apresenta um rol de termos referidos a elas: atitudes, valores, julgamentos, axiomas, opiniões, ideologia, percepções, conceituações, sistema conceitual, pré-conceituações, disposições, teorias implícitas, teorias explícitas, teorias pessoais, processo 
mental interno etc. Na sequência, ampliando a relação de Pajares, cita Gimenez (1994) e Garcia (1995), acrescentando os seguintes termos: teorias populares, conhecimento prático pessoal, perspectiva, construções pessoais, epistemologias, modos pessoais de entender, filosofias instrucionais, dentre outros.

Félix (1998), em estudo de base etnográfica, salienta a importância de se diferenciar crença e conhecimento, e, ao observar os comentários de alguns estudiosos sobre o assunto, apresenta uma definição, apontando que o conhecimento é o resultado cognitivo do pensamento, enquanto a crença é o resultado afetivo, sendo composta de "emoções, sentimentos, percepções, avaliações subjetivas, estados de espírito, lembranças de experiências pessoais, pressuposições sobre a existência de entidades e mundos alternativos [...]" (FÉLIX, 1998, p. 33).

A mesma autora destaca que o conhecimento é cumulativo e muda de acordo com as normas de argumentação. Já as crenças são menos maleáveis, são relativamente estáticas, porque a emoção parece estar retida na memória longa ${ }^{2}$; quando elas mudam, é mais uma questão de conversão do que o resultado de argumentação ou evidências.

Para Barcelos (2007), a crença é tão antiga quanto nossa existência, pois, desde que o homem começou a pensar, ele passou a acreditar em algo. A autora define crenças como

... uma forma de pensamento, construções da realidade, maneiras de ver e perceber o mundo e seus fenômenos, co-construídas em nossas experiências resultantes de um processo interativo de interpretação e (re)significação. Como tal, crenças são sociais (mas também individuais), dinâmicas, contextuais e paradoxais. (BARCELOS, 2007, p. 113).

Barcelos (2007) explica que se trata de uma definição mais recente, a qual - contrariando a visão de que as crenças são estáticas - caracteriza-as como dinâmicas, argumentando, a partir de uma visão sociocultural, que elas mudam através do tempo, o que não significa, entretanto, que elas são geradas

${ }^{2}$ Para mais esclarecimentos sobre memória longa, ver Helene e Xavier (2004). 
imediatamente. Elas se apoiam em fatos ocorridos no passado, em opiniões de pessoas que foram importantes, em assuntos veiculados pela mídia, entre outros.

A pesquisadora salienta que as crenças são "socialmente construídas e situadas contextualmente". À medida que as pessoas interagem e modificam suas experiências, são também modificadas por elas; assim, as crenças "incorporam as perspectivas sociais, pois nascem no contexto da interação e na relação com os grupos sociais" (BARCELOS, 2007, p. 114). A autora ainda destaca o fato de as crenças serem paradoxais e contraditórias, no sentido de que, ao mesmo tempo em que são sociais, as crenças também são individuais e únicas, porque cada pessoa assimila uma experiência de modo particular.

Interessantes também são as observações de Yero (2010), em seu livro Teaching in mind, cujo objetivo é avaliar as experiências subjetivas, as crenças, os valores, os pressupostos, as metáforas e os significados que modelam o mundo pessoal de um professor, procurando mostrar como as crenças sobre ensino, aprendizagem e alunos influenciam as percepções, os comportamentos e todas as decisões voltadas à questão do ensino. Para tanto, a estudiosa examina, dentre outras coisas, a diferença entre "fatos" e "crenças", expondo que os primeiros são declarações que fazem parte do consenso da realidade, havendo pouca dúvida sobre sua veracidade; são elementos para os quais existe um corpo enorme de apoio e sem evidências contraditórias, sendo raramente questionados. Entretanto, quanto mais complexa uma situação, quanto mais perspectivas possíveis se podem ter e quanto mais pessoas diferentes estão envolvidas, menos provavelmente se pode declarar tratar-se de um fato. Entra-se, assim, no campo das crenças, que ela define como "julgamentos e avaliações que fazemos sobre nós mesmos, sobre os outros e sobre o mundo que nos rodeia" (YERO, 2010, p. 28, tradução nossa).

Yero (2010) sugere que uma forma possível de distinguir entre o conhecimento factual e a crença é observar como uma pessoa responde a um desafio. Exemplifica o caso de alguém apontando que uma pessoa digitou uma palavra incorretamente; essa pessoa geralmente não sente a necessidade de defender o erro de digitação, ela simplesmente muda um pouco a sua atenção para resolver o problema. Mas, quando alguém questiona as crenças 
de uma pessoa, ela frequentemente responde como se isso fosse uma ameaça pessoal, defendendo emocionalmente sua posição. "Isso porque as crenças são pessoais... elas são tão parte de nós como nosso nome ou nossa perna" (YERO, 2010, p. 28, tradução nossa).

A autora argumenta, ainda, que as crenças não apenas afetam a forma como as pessoas se comportam ${ }^{3}$, mas também o que elas percebem em seu ambiente. E afirma que, ao contrário do que diz o ditado "ver para crer", é mais provável que seja "crer para ver". Ou seja, quando as pessoas acreditam que algo é verdadeiro, elas percebem a informação que confirma essa crença, percebem o que elas esperam/querem perceber. E exemplifica: "Se, por exemplo, Stan crê que Jamie é um encrenqueiro, ele inconscientemente interpretará alguns dos comportamentos de Jamie como perturbadores. Cheryl, que crê que Jamie é cheio de energia, pode não observar o mesmo comportamento" (YERO, 2010, p. 30, tradução nossa).

\subsection{Atitudes}

Assim como as crenças, definir "atitude" não é das tarefas mais fáceis, porque esse termo também está associado a campos diversos; daí se ouvirem expressões como atitude cristã, atitude corajosa, atitude preconceituosa, atitude positiva, atitude negativa, atitude política, atitude sustentável, atitude linguística...

Além disso, é muito estreito o limite entre os significados, por exemplo, de "atitude" e "comportamento", "atitude" e "postura", "atitude" e "procedimento", que, muitas vezes, são expressões tomadas como sinônimas, mas que, na verdade, podem não o ser, dependendo do contexto em que se encontrem.

Em sentido lato, atitude significa "posição, postura; modo de proceder ou agir; comportamento, procedimento; postura reveladora das disposições do ânimo para agir, reveladora dos sentimentos; reação ou maneira de ser, em relação a determinada(s) pessoa(s), objeto(s), situações etc." (NASCENTES, 1981; BORBA, 2004; FERREIRA, 2009; HOUAISS, 2009).

${ }^{3}$ Embora as crenças representem forte influência no comportamento ou na ação, nem sempre as pessoas agem de acordo com suas crenças. Isso será discutido posteriormente, ao se falar sobre "atitudes". 
Para este trabalho, entretanto, interessa o sentido restrito de atitude, voltado à ciência linguística que, por sua vez, tomou emprestado o seu sentido da Psicologia Social.

Segundo Lambert e Lambert (1972, p. 7), a Psicologia Social é "o estudo experimental dos indivíduos, examinados no seu enquadramento social e cultural". Afirmam os autores que o exame das atitudes se converteu em uma preocupação importante dos psicólogos sociais por se tratar de um fenômeno psicológico complexo que se reveste de grande significado social. Para eles,

Atitude é uma maneira organizada e coerente de pensar, sentir e reagir em relação a pessoas, grupos, questões sociais ou, mais genericamente, a qualquer acontecimento ocorrido em nosso meio circundante. Seus componentes essenciais são os pensamentos e as crenças, os sentimentos (ou emoções) e as tendências para reagir. (LAMBERT; LAMBERT, 1972, p. 78).

As atitudes desempenham uma função essencial na determinação do nosso comportamento; por exemplo, afetam nossos julgamentos e percepções sobre outros, ajudam a determinar os grupos com que nos associamos, as profissões que finalmente escolhemos e até as filosofias à sombra das quais vivemos (LAMBERT; LAMBERT, 1972, p. 83).

Rodrigues (1972), baseando-se em vários conceitos apresentados nos manuais de Psicologia Social surgidos entre 1962 e 1971, resume atitude social como "uma organização duradoura de crenças e cognições em geral, dotada de carga afetiva pró ou contra um objeto social ${ }^{[4]}$ definido, que predispõe a uma ação coerente com as cognições e afetos relativos a este objeto" (RODRIGUES, 1972, p. 397).

A Psicologia Social, até o final da década de 60, não se interessava pelo aspecto sociocultural da linguagem nem por questões sociolinguísticas,

${ }^{4}$ Conforme já se destacou, o objeto social pode ser uma teoria, situação, acontecimento, língua, dialeto, grupo, pessoa, etc. 
servindo-se da linguagem somente como um instrumento para obter dados. Coube a Wallace Lambert (2003), precursor dos estudos sobre atitudes linguísticas, a preocupação com os aspectos social, ideológico e cultural da linguagem, a partir da publicação, em 1967, do artigo A Social Psychology of Bilingualism, no Journal of Social Issues.

O propósito desse trabalho era estender e integrar os interesses dos psicólogos, dos linguistas e dos antropólogos com relação ao bilinguismo. Interesse que incluía preocupações como o processo de troca bilíngue e o desenvolvimento dessa habilidade com as implicações neurológicas e mentais envolvidas; a competência do bilíngue nos dois sistemas linguísticos e a maneira como esses sistemas interagem; a preocupação com as configurações socioculturais do bilinguismo e os efeitos do comportamento bilíngue.

Em seu artigo, Lambert (2003) ainda apresenta os resultados de trabalhos conduzidos por ele e por um grupo de estudiosos na Universidade McGill, em Montreal, utilizando a técnica matched guise, também conhecida como técnica dos "falsos pares".

Tal técnica foi desenvolvida com o propósito de inferir e medir atitudes. Consiste em apresentar a um grupo de “juízes” (ouvintes que farão julgamentos) gravações de falantes perfeitamente bilíngues lendo a mesma passagem de um texto duas vezes: em um primeiro momento, na própria língua (por exemplo, o francês) e, em um segundo momento, em outra língua (por exemplo, o inglês). A esses juízes é requerido que ouçam as gravações e que avaliem as características pessoais de cada falante usando apenas as pistas vocais e de leitura. Nessa avaliação, apresentam-se características positivas e negativas relacionadas a itens como competência (p. ex.: inteligência, autoconfiança, ambição), integridade pessoal (p. ex.: sinceridade, caráter, confiabilidade), atratividade social (p. ex.: sociabilidade, empatia, senso de humor). Os juízes, entretanto, não têm o conhecimento de que, na verdade, trata-se das mesmas pessoas ora lendo o texto em uma língua, ora lendo-o em outra. Assim, quaisquer diferenças em seus julgamentos sobre a personalidade dos falantes (isto é, atribuir a um falante características positivas quando ele lê o texto em uma língua e negativas quando ele o lê em outra língua) representariam atitudes estereotipadas em relação aos membros de um grupo etnolinguístico específico. 
Labov (2008) refere-se à técnica matched guise como o instrumento básico amplamente utilizado para o estudo de reações subjetivas à linguagem, destacando:

O princípio essencial que emerge do trabalho de Lambert é o de que existe um conjunto uniforme de atitudes frente à linguagem que são compartilhadas por quase todos os membros da comunidade de fala, seja no uso de uma forma estigmatizada ou prestigiada da língua em questão. Essas atitudes não emergem de forma sistemática se a pessoa for questionada diretamente sobre os dialetos; mas se ela fizer dois conjuntos de julgamentos de personalidade sobre o mesmo falante usando duas formas diferentes de língua, e se não perceber que é o mesmo falante, suas avaliações subjetivas da língua emergirão como diferenças nas duas pontuações (LABOV, 2008, p. 176).

Labov (2008) menciona que a técnica desenvolvida por Lambert e seus colaboradores trouxe um progresso considerável na mensuração das reações sociais inconscientes à linguagem e proporcionou uma metodologia segura e uma série de princípios empíricos para o estudo das reações subjetivas.

A partir do final da década de 1960, então, “atitude” passa a ser tema de interesse não só dos psicólogos sociais, mas também dos linguistas, especialmente daqueles que se dedicavam à área da Sociolinguística, sobretudo em pesquisas voltadas para o assunto de línguas e dialetos em contato. Assim, de uma perspectiva agora linguística, apresentam-se algumas definições para atitudes.

Giles, Ryan e Sebastian (1982, p. 7) definem atitudes linguísticas "como qualquer índice cognitivo, afetivo ou comportamental de reações avaliativas, em direção às variedades diferentes de língua ou de seus falantes".

Para Moreno Fernandéz (1998, p. 179, tradução nossa), "A atitude linguística é uma manifestação da atitude social dos indivíduos, distinguida por centrar-se e referir-se especificamente tanto à língua como ao uso que dela se faz em sociedade [...]”. Ressalta o autor que, ao falar de língua, está incluindo qualquer tipo de variedade linguística (atitudes face aos estilos diferentes, socioletos diferentes, dialetos diferentes ou línguas naturais 
diferentes). Para ele, as atitudes linguísticas são o reflexo das atitudes psicossociais, de modo que é difícil delimitar onde começa a atitude em relação a uma variedade linguística e onde termina a atitude quanto ao grupo social ou ao usuário dessa variedade.

Na mesma linha, Bergamaschi (2006) afirma, citando Grosjean (1982), que as atitudes ou os posicionamentos em relação à língua refletem as atitudes ou os posicionamentos em relação aos usuários dela. A autora destaca que não se sabe muito sobre atitudes e emoções orientadas a respeito da língua que vão da lealdade à aversão linguística -, mas elas são, em parte, responsáveis pela manutenção ou pela mudança linguística.

Aguilera (2008) destaca que as atitudes de valorização ou de rejeição às variedades de língua em uso são reguladas pelos grupos sociais de maior prestígio social, ou os mais altos na escala socioeconômica, os quais ditam o que tem prestígio e status. Prestígio e status relacionam-se com o reconhecimento da sociedade às pessoas em função da condição socioeconômica e cultural que possuem (poder aquisitivo, capacidade intelectual, posição social, entre outros).

Segundo Bisinoto (2007), não é tarefa fácil definir "atitude linguística” e não há consenso entre os estudiosos em relação ao conceito desse termo e, após expor o posicionamento de vários autores, propõe que se utilize o termo "atitude sociolinguística", justificando que a atitude linguística e a social complementam-se na forma como os indivíduos agem e reagem. Destaca Bisinoto (2007, p. 24):

As avaliações manifestas e encobertas, subjetivas e objetivas, mais ou menos conscientes, relativas à linguagem dos homens numa sociedade plural, têm a propriedade de fundar e governar tanto as relações de poder quanto o prestígio ou o desprestígio das formas lingüísticas, estabelecendo seletividades, evidenciando preconceitos.

Segundo Appel e Muysken (1996) e López Morales (2004), há dois grupos de definição de atitudes: as mentalistas e as condutistas. A definição mentalista caracteriza atitude como um estado de disposição mental, uma variável que intervém entre um estímulo que afeta a pessoa e sua resposta a ele. Essa concepção traz consigo um problema metodológico: o fato de a 
atitude não ser observável nem analisável diretamente, de forma que se torna difícil determinar o tipo adequado de dados a partir dos quais se podem inferir as atitudes bem como elaborar um mecanismo apropriado para medir algo que "carece de forma manifesta".

Já a concepção condutista, que se baseia nas respostas dos falantes frente a certas situações sociais, pode ser estudada diretamente, correspondendo a um método de aplicação seguro; entretanto tem o inconveniente de não predizer a conduta verbal e, assim, não pode constituirse em padrões sistemáticos e coerentes.

Afirma López Morales (2004) que a maior parte das investigações linguísticas ampara-se na perspectiva mentalista, por essa ter caráter preditivo. Os mentalistas visualizam a atitude como uma estrutura componencial múltipla, formada pelos elementos afetivo (emoções e sentimentos), cognitivo (inclui as percepções, as crenças e os estereótipos presentes no indivíduo) e comportamental (tendência a atuar e a reagir de certa maneira com respeito ao objeto). Já os condutistas a concebem como unidade indivisível.

Também Moreno Fernández (1998) atesta as afirmações de López Morales e acrescenta que, entre aqueles que defendem a concepção mentalista e que interpretam a atitude como uma entidade complexa, existem discordâncias para determinar como esses conceitos estabelecem relações entre si e todos eles com a atitude; constituindo-se um problema descobrir a estrutura componencial das atitudes linguísticas.

\subsubsection{Componentes da atitude}

Segundo Lambert e Lambert (1972), Rodrigues (1972), Moreno Fernández (1998), López Morales (2004), dentre outros estudiosos, as atitudes são integradas por três componentes: cognitivo, afetivo e comportamental. Lambert e Lambert (1972) explicam que, para que uma atitude se constitua, é necessário que esses três componentes estejam inter-relacionados de tal forma que aquilo que se sente e a maneira como se reage diante de um objeto social estejam coerentemente associados ao modo como se pensa a respeito dele.

O componente cognitivo refere-se às crenças, aos pensamentos, aos conhecimentos que se tem em relação a um objeto social definido. Não se 
pode ter uma atitude em relação a um objeto se não houver alguma representação cognitiva a seu respeito, ou seja, é preciso conhecê-lo. Ninguém pode manifestar uma reação pró ou contra aquilo que desconhece. Rodrigues (1972, p. 398) assevera que as atitudes preconceituosas são resultado de cognições negativas em relação ao grupo que é objeto de discriminação, e exemplifica: "Pessoas que não gostam de índios consideram-nos selvagens, ameaçadores, ignorantes, hostis, infradotados intelectualmente, bestiais, etc.".

$\mathrm{O}$ componente afetivo diz respeito às emoções e aos sentimentos pró ou contra um objeto social e é considerado por alguns estudiosos, como Fishbein (1965 apud RODRIGUES, 1972), o único elemento característico das atitudes sociais. Rodrigues, referindo-se aos estudos de Fishbein, expõe que as crenças e os comportamentos associados a uma atitude são apenas elementos pelos quais se pode medir a atitude, entretanto não são parte integrante dela. Embora as crenças que uma pessoa possui possam suscitar um afeto positivo ou negativo em relação a um objeto e predispor à ação, não são necessariamente impregnadas de conotação afetiva.

Também Moreno Fernández (1998) faz referência a Fishbein, destacando-o como autor de uma das propostas psicossociológicas mais conhecidas sobre os componentes das atitudes, e salienta que esse autor desmembra atitudes e crenças, tomando a primeira como formada apenas pelo componente de natureza afetiva, fundamentando-se em valoração subjetiva e sentimental em relação a um objeto; já a segunda, pondera Fishbein, é formada pelos componentes cognoscitivo e conativo ${ }^{5}$.

Para melhor compreensão do exposto por Fishbein, Rodrigues (1972) apresenta o exemplo de alguém que pode crer na existência de vida fora da Terra, porém manter essa crença em um nível cognitivo, sem unir a isso qualquer traço afetivo, ou seja, ela pode manter-se neutra quanto a esse assunto. Não se poderia dizer, então, que tal pessoa tem uma atitude em relação à existência de vida em outros planetas. Diferentemente de ufologistas que, certamente, acrescentariam uma conotação afetiva às suas cognições a respeito desse tema e demonstrariam isso se engajando em discussões acaloradas.

O componente comportamental ou conativo é entendido como conduta, reação ou tendência à reação diante de um objeto social. De acordo com

${ }^{5}$ De conação, na Psicologia, tendência consciente para atuar, agir. 
Rodrigues (1972, p. 400), há uma posição geralmente aceita pelos psicólogos sociais de que "as atitudes possuem um componente ativo, instigador de comportamentos coerentes com as cognições e os afetos relativos aos objetos atitudinais". Assim, uma fã de um cantor ou de um ator traz consigo cognições e afetos em relação a essa pessoa capazes de, em uma situação como um show ou um filme, fazê-la ter comportamentos coerentes com essas cognições e afetos, por exemplo, gritar, chorar, ficar histérica, dançar, cantar etc. Entretanto, nem sempre as pessoas se comportam de forma coerente com suas cognições e afetos, daí a expressão "tendência à reação" com o intuito de indicar que as atitudes "não se encontram necessariamente expressas no comportamento ostensivo".

Lambert e Lambert (1972) observam que o êxito da interação social depende da habilidade que se tem para inferir ou deduzir pensamentos, sentimentos e tendências reativas alheias, por meio de "pistas" que podem ser captadas pelo tipo de comportamento das pessoas. Reforçam os autores ser comum as pessoas regularem suas atitudes em função daquilo que presumem do outro.

Corroborando com Fishbein, López Morales (2004) separa o conceito de crença do conceito de atitude; porém opõe-se àquele pesquisador quanto ao componente formador da atitude. Para López Morales (2004), a atitude está dominada apenas pelo traço comportamental, por condutas que podem ser positivas, de aceitação, ou negativas, de rejeição; uma atitude nunca pode ser neutra. Já as crenças podem estar integradas por elementos cognitivos e/ou afetivos. Nos elementos cognitivos, incluem-se as percepções, os conhecimentos, os estereótipos presentes no indivíduo; nos afetivos, estão presentes as emoções e os sentimentos. Podem-se resumir as relações entre crenças e atitudes por meio da figura a seguir: 


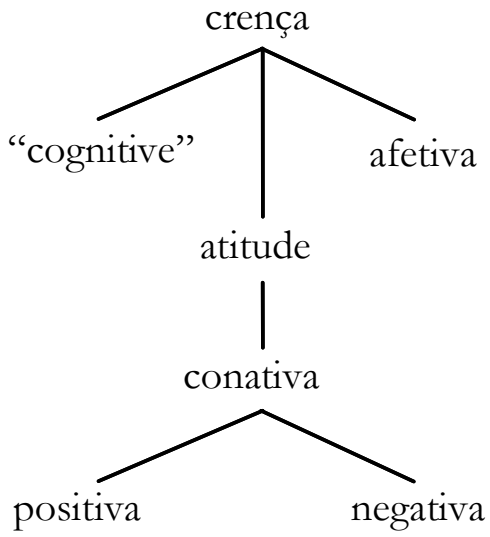

Figura 1 - Relação entre crença e atitude, segundo López Morales.

Conforme já se destacou, compartilha-se, neste estudo, da visão de López Morales (2004), entendendo-se a atitude como constituída apenas do componente comportamental. Na verdade, o que se defende a respeito desse assunto é que a crença é "maior", ela contém a atitude, ou melhor, ela contém os três componentes que normalmente são atribuídos à atitude: o conhecimento, o sentimento e o comportamento, o que pode ser bem observado por meio da Figura 1. Acredita-se que as crenças determinam o comportamento dos indivíduos, no sentido de que são elas que detêm os valores, os julgamentos, as opiniões que uma pessoa tem sobre os outros, sobre o mundo e sobre si mesma. Elementos esses carregados de informações e de sentimentos que, geralmente ${ }^{6}$, vão produzir atitudes.

Essas considerações mostram a importância de se refletir sobre como as atitudes se formam.

"Considera-se "geralmente" porque, conforme atesta López Morales (2004), nem todas as crenças geram atitudes, mas a maior parte delas implica valoração e pode estar baseada em fatos reais (algo que efetivamente existe) ou pode não ter motivação empírica (ao conhecer uma pessoa, por exemplo, pode-se crer que é antipática sem nunca ter conversado com ela antes, sem saber coisa alguma a seu respeito, sem ela ter dado qualquer motivo para que se pense assim). 


\subsubsection{Formação/Desenvolvimento das atitudes}

As atitudes não são características inatas às pessoas, elas são formadas e aprendidas no processo de socialização. Segundo Lambert e Lambert (1972), as atitudes são hábitos complexos, no sentido de que são formas aprendidas de ajustamento. A função de ajustamento social das atitudes desempenha o papel de propiciar às pessoas oportunidade de uma boa acomodação social, possibilitando a manutenção mais harmoniosa ou menos harmoniosa de nossas relações com outras pessoas. Seu desenvolvimento deve obedecer a três princípios fixos de aprendizagem inter-relacionados: os princípios de associação, de transferência e de satisfação de necessidades.

Os sentimentos e as tendências reativas são aprendidos, na maioria das vezes, por meio da associação e da satisfação de necessidades. Assim, evitam-se pessoas ou coisas associadas a episódios desagradáveis e aproxima-se das associadas com acontecimentos agradáveis. Muitas vezes, a incapacidade de o indivíduo compreender por qual motivo ele sente e reage de uma maneira específica diante de um objeto social o leva a observar os pensamentos e as crenças alheias, podendo adotá-los para justificar seus próprios sentimentos e tendências reativas. Observa-se, então, nesse caso, o princípio de transferência. É por meio da observação, da identificação e da imitação de "professores" sociais (pais, familiares, amigos, professores, figuras públicas...) que se aprendem e se formam as atitudes.

Lambert e Lambert (1972, p. 99) alegam que, ao se sentir "atraído" por um "professor" social, o indivíduo passa a desejar ser como ele. Esclarecem que "quanto mais digna de confiança e mais atraente é uma pessoa, tanto mais probabilidade de sua mensagem penetrar e influenciar as atitudes existentes".

A partir do momento em que as atitudes estão desenvolvidas, elas conferem regularidade à maneira de reagir e de se ajustar socialmente, ou seja, haverá uma tendência para reagir da mesma forma sempre que o indivíduo for exposto a uma situação semelhante. A aprendizagem e a formação de atitudes ocorrem ao longo da vida; mas, nas primeiras fases de desenvolvimento (infância e adolescência), seus componentes não estão tão rigidamente sistematizados que não possam ser modificados por novas experiências. Já na fase adulta, "sua organização pode-se tornar inflexível e 
estereotipada, especialmente para aquelas pessoas que foram encorajadas, no decurso de grandes períodos de tempos, a reagir segundo processos padronizados ou 'aceitáveis' a determinados acontecimentos e grupos" (LAMBERT; LAMBERT, 1972, p. 78).

\subsubsection{Modificação das atitudes}

Apesar da aparente estabilidade das atitudes, experiências vividas ao longo da vida podem levar à sua alteração; entretanto esse processo não é simples, sendo muito mais difícil mudar atitudes do que aprendê-las, já que, depois de desenvolvidas, as atitudes convertem-se em elementos integrantes da personalidade do indivíduo, influindo em seu comportamento.

Lambert e Lambert (1972) ressaltam que modificá-las implica mudança nos três princípios de aprendizagem vistos anteriormente. Assim, uma atitude pode ser alterada se o indivíduo perceber (i) que é proveitoso mudar para alcançar um objetivo específico; (ii) para adentrar um grupo; (iii) para ganhar status, prestígio; (iv) para obter vantagens, em resumo, para satisfazer uma necessidade. Da mesma forma, pode ocorrer mudança de atitude se houver condições adequadas para aprender novos sentimentos e reações por meio da associação; se, por exemplo, o indivíduo que havia passado por uma experiência negativa com um objeto social obtém novas e agradáveis experiências com esse mesmo objeto, as atitudes que antes eram de rejeição podem passar a ser atitudes positivas. Ao receber uma informação nova a respeito de um objeto social, as pessoas levam em conta os "agentes" ou "professores" sociais que transmitem essa informação; a depender da eficácia desses agentes, os indivíduos podem alterar suas atitudes por meio da transferência.

Rodrigues (1972) ensina que as características necessárias a tais agentes são a competência e a credibilidade. E relata o caso de uma pesquisa em que se apresentou a dois grupos diferentes o mesmo conjunto de versos, com o intuito de que avaliassem a qualidade das estrofes; porém, para um grupo, atribuiu-se o conjunto de versos a um poeta de renome e, para o outro grupo, a autoria foi imputada a uma estudante universitária. Os resultados mostraram que as atitudes foram diferenciadas e que a fonte de maior prestígio foi julgada com atitudes muito mais positivas do que a fonte sem prestígio. 
Esse resultado revela "uma mudança de objeto de julgamento em vez de uma mudança no julgamento do objeto” (RODRIGUES, 1972, p. 438), já que se trata do mesmo objeto. O poema e o poeta de renome formam um todo, tal como a língua e os usuários dela, que também formam um todo e, assim como já se destacou anteriormente, é difícil delimitar onde começa a atitude em direção a uma variedade linguística e onde termina a atitude face ao grupo social ou ao usuário dessa variedade.

\section{Conceitos Importantes para os Estudos de Crenças e Atitudes Linguísticas}

Em um estudo de Crenças e Atitudes Linguísticas, há conceitos fundamentais que não podem deixar de ser abordados, mesmo que brevemente, como se fará nesta subseção. Trata-se de definir termos como identidade linguística, lealdade e deslealdade linguística, status/prestígio linguísticos, preconceito, estigma e estereótipo.

\subsection{Identidade linguística}

Em relação à identidade linguística, Moreno Fernández (1998, p. 180) anuncia que identidade representa "aquilo que permite diferenciar um grupo do outro, uma etnia de outra, um povo de outro". Ela pode ser definida de maneira objetiva ou subjetiva. Objetivamente falando, a identidade se caracterizaria pelas instituições que a constituem e por suas peculiaridades culturais. Subjetivamente, a identidade de um grupo pode ser reconhecida pelo sentimento de comunidade compartilhado por seus membros e pela forma como se diferenciam de outros grupos.

Na mesma linha, Uflacker e Schneider (2008, p. 33), apoiadas em McNamara (1997), expõem que identidade é “o conceito que o indivíduo tem de si próprio derivado do reconhecimento do pertencimento a determinado grupo social e relacionado com a significação emocional vinculada a essa pertença". Esse sentimento de pertença se revela por meio do uso da linguagem, em que as representações de crenças e diferentes identidades sociais se mostram por atitudes linguísticas. Segundo as autoras, a diversidade linguística é mantida por relações de poder e de força entre os 
diferentes grupos sociais. Essas relações revelam a posição que as pessoas ocupam na estratificação social bem como a linguagem que utilizam.

Silva, T. (2000) interpreta a identidade como algo inseparável da diferença. Segundo ele, é na diferença que a identidade se revela. Assim, ao dizer "sou brasileiro", o indivíduo está negando todas as outras possíveis nacionalidades. Logo dizer "sou brasileiro" equivale a dizer "não sou argentino", "não sou mexicano", "não sou francês" etc. Para o teórico, identidade e diferença compartilham a característica de serem o resultado de atos de criação linguística. Quer dizer, elas não são elementos da natureza que existem por si só; elas necessitam ser produzidas e essa produção se dá no contexto das relações culturais e sociais. Por se estabelecerem na relação social, identidade e diferença estão sujeitas a conjuntos de força e de relação de poder. Nas palavras de Silva, T. (2000, p. 81):

Elas não são simplesmente definidas; elas são impostas. Elas não convivem harmoniosamente, lado a lado, em um campo sem hierarquias; elas são disputadas.

[...] Na disputa pela identidade está envolvida uma disputa mais ampla por outros recursos simbólicos e materiais da sociedade. A afirmação da identidade e a enunciação da diferença traduzem o desejo dos diferentes grupos sociais, as simetricamente situados, de garantir o acesso privilegiado aos bens sociais. A identidade e a diferença estão, pois, em estreita conexão com relações de poder.

Para Woodward (2000), a identidade é relacional, isto é, a identidade de um grupo linguístico qualquer depende da identidade de outro grupo para existir, estando sujeita, portanto, a uma identidade "que ela não é". Nesse sentido, a identidade é marcada pela diferença e isso, em muitos casos, tem consequências negativas, pois algumas diferenças são vistas de forma mais importante que outras, fazendo que as pessoas sejam "rotuladas" como pertencentes a determinados grupos ou classes sociais. O ponto é: por que alguns significados são preferidos relativamente a outros? Nas palavras da autora: "Todas as práticas de significação que produzem significados envolvem relações de poder, incluindo o poder para definir quem é incluído e quem é excluído" (WOODWARD, 2000, p. 18). 
A mesma autora sugere ainda que a identidade pode ser submetida aos fenômenos da globalização, que produzem homogeneidade cultural e promovem o distanciamento da identidade do indivíduo em relação à sua comunidade e à cultura local. Isso pode gerar como consequência a resistência ao próprio dialeto, prestigiando algumas identidades nacionais e locais em detrimento da própria identidade.

\subsection{Lealdade e deslealdade linguística}

Lealdade e deslealdade linguística são, obviamente, termos que se opõem, mas que têm sua origem em um ponto comum: na atitude do falante frente a seu grupo linguístico ${ }^{7}$. Essa atitude pode ser positiva ou negativa: sendo positiva, apresenta-se a situação de lealdade linguística; sendo negativa, tem-se o caso de deslealdade linguística.

Conforme já se destacou no item identidade linguística, alguns indivíduos podem se desviar da identidade linguística de seu grupo. As razões para que isso ocorra podem ser várias, desde o pertencimento a uma comunidade linguística cujo status seja baixo e com a qual a pessoa não quer ser identificada, até as pressões de outros grupos com os quais convive. Ao rejeitar sua identidade linguística, mudando seu modo de falar para sugerir origens sociais ou regionais que na verdade não possui, o falante está revelando uma deslealdade linguística.

De acordo com Appel e Muysken (1996), os membros de grupos sem prestígio social ou de minorias linguísticas têm consciência de que a língua de seu grupo não lhes serve para alcançar ascensão social; porém o fato de reconhecerem isso e de mostrarem atitudes negativas em relação à sua própria língua não significa que eles não a tenham em consideração.

Frosi, Faggion e Dal Corno (2010), apoiadas na designação dada por Weinrich ao termo lealdade linguística em sua célebre obra sobre línguas em contato, esclarecem que a lealdade à língua encerra dois objetivos: indica a preocupação em afastar a língua de possíveis interferências de uma outra língua próxima e o esforço em utilizá-la sempre que possível. Quanto a este

\footnotetext{
Usa-se grupo linguístico aqui de forma ampla, podendo referir-se à língua, ao dialeto, ao falar de um país, região, comunidade, etc.
} 
último objetivo, Bergamaschi (2006) esclarece que pode ser uma forma de conservadorismo, observada mais frequentemente nos membros mais velhos do grupo ou nos falantes que moram nas zonas rurais.

Em síntese, a lealdade linguística está estreitamente vinculada ao orgulho de pertencimento a determinado grupo. Orgulho esse que geralmente está ligado ao poder e ao status que determinados grupos linguísticos possuem, referentes à sua posição social, econômica e/ou cultural. Na contramão, a deslealdade linguística reporta-se ao sentimento de vergonha, de inferioridade, de insegurança e, em casos mais graves, até de aversão linguística.

\subsection{Status/prestígio linguístico}

Aplica-se, frequentemente, o termo status para aludir a algo positivo, de destaque, elevado socialmente. Todavia, o sentido lato da palavra status não remete, necessariamente, a algo positivo, mas sim a "situação, estado ou condição de alguém ou algo, perante a opinião das pessoas ou em função do grupo ou categoria em que é classificado" (FERREIRA, 2009). É com esse sentido que Camara Jr. (1975) usa a palavra status, quando atesta que a linguagem de determinado grupo social é capaz de refletir esse grupo tão bem quanto outras formas de comportamento. Ou seja, é possível conhecer o grupo pelo modo como ele se manifesta linguisticamente, de forma que essa linguagem vem a ser uma marca de status social.

Já a Antropologia Social define o termo status como "o grau de distinção ou de prestígio, ou a situação hierárquica de um indivíduo ou grupo de indivíduos perante os demais membros de seu grupo social”. Assim, status linguístico e prestígio linguístico são tomados como sinônimos.

Moreno Fernández (1998) considera o prestígio tanto como conduta quanto como atitude. Assim, ele pode ser algo que o indivíduo ou o grupo possui e ostenta, mas pode ser também algo que se concede, que se atribui. Neste último sentido, o autor define prestígio como "um processo de concessão de estima e respeito aos indivíduos ou aos grupos que reúnem certas características e que leva à imitação das condutas e crenças desses indivíduos ou grupos" (MORENO FERNÁNDEZ, 1998, p. 189).

As normas de prestígio não são fixas, variam de um grupo social a outro, e essa variação depende de questões sociais, econômicas, culturais, 
políticas, religiosas, históricas, linguísticas com as quais os indivíduos se identificam ou, ao contrário, das quais se diferenciam; a única mais ou menos fixa é aquela relacionada à norma linguística de prestígio, aquela que se tornou historicamente objeto privilegiado de estudo e que representa o grupo dominante, constituído por pessoas mais escolarizadas e de poder aquisitivo mais elevado.

\subsection{Preconceito linguístico}

Nos dicionários, registra-se preconceito (de pré + conceito) como "qualquer idéia, opinião ou sentimento desfavorável, formado antecipadamente, sem exame crítico" (BORBA, 2004; FERREIRA, 2009; HOUAISS, 2009).

$\mathrm{O}$ termo preconceito linguístico refere-se à atitude negativa frente a determinado grupo linguístico sem razão aparente. Normalmente está voltado a grupos linguísticos que detêm pouco ou nenhum prestígio social, a minorias linguísticas, a grupos linguísticos que representam falares diferentes do falar daquele que avalia preconceituosamente o outro.

É comum verificar os termos preconceito e estigma sendo usados como formas sinônimas. Embora os dois termos sejam utilizados para fazer uma avaliação negativa, há, entre os dois, diferenças relativas ao grau dessa avaliação. Parece que, em relação ao preconceito, a atitude negativa frente ao elemento que está sendo objeto de avaliação é menor do que no caso do estigma. Desse modo, aparentemente, o estigma está impregnado de uma aversão ausente no preconceito.

De acordo com Bergamaschi (2006, p. 46), “O estigma vai além do preconceito, é mais forte e mais inibidor. Este termo remete a atitudes negativas, que marcam o estigmatizado para o resto da vida".

O preconceito linguístico seria, assim, um "estigma amenizado".

\subsection{Estigma}

Os dicionários registram a palavra estigma com sentido denotativo e conotativo. No primeiro caso, estigma significa "marca, sinal, cicatriz"; no sentido figurado, a palavra remete a "rótulo", "aquilo que é considerado indigno, desonroso” (BORBA, 2004; FERREIRA, 2009; HOUAISS, 2009). 
Para os estudos de Crenças e Atitudes, importa observar o sentido conotativo dessa palavra que, segundo explica Goffman (1988), é uma criação grega para referir-se a sinais corporais, mas que, a partir da Era Cristã, passou a ter significados metafóricos os quais evoluíram para os sentidos que existem hoje. Na acepção que interessa a este estudo, e usando os termos de Goffman (1988, p. 13), estigma é um “atributo profundamente depreciativo", de modo que o indivíduo (falante) estigmatizado (imperfeito, inferior) é vítima de preconceitos, de discriminações, de animosidades.

Carregar um estigma linguístico significa, então, carregar uma marca que identifica negativamente o falante e, por isso, geralmente ele procura escondê-la. Por exemplo: se um falante de dialeto que usa o /r/ retroflexo tenta produzir, no seu discurso oral, outra variante (um tepe, talvez?), ele está tentando esconder o estigma de sua identidade linguística. Diz-se "esconder" e não “apagar”, porque, assim como não é possível apagar uma cicatriz, não é possível apagar a identidade linguística. Pode-se ocultá-la, mas, em algum momento, ela se revelará, como uma cicatriz que se tenta esconder por baixo da roupa, mas que um movimento descuidado pode fazer aparecer.

\subsection{Estereótipo}

Ensina Labov (2008, p. 360) que estereótipos "são formas socialmente marcadas, rotuladas enfaticamente pela sociedade". Esse rótulo que se impõe sobre determinados grupos linguísticos está pautado nos julgamentos sobre as pessoas, nas crenças que o indivíduo carrega a respeito de um traço linguístico, nos conhecimentos sobre um grupo e sua cultura, nos preconceitos em relação à língua e aos falantes dessa língua.

Orsi (2008) afirma que o estereótipo pode ser entendido como uma generalização desfavorável, exagerada e simplista sobre um grupo ou uma categoria de pessoas. Exagerada e simplista porque os rótulos colocados nos indivíduos não têm, na maioria das vezes, uma base sólida para se sustentar. São quase sempre impressões sem fundamento, expressas por perceber no outro algo diferente do que existe em si, algo que geralmente incomoda porque faz parte de outra realidade linguística, social, cultural...

${ }^{8}$ Não interessa a este trabalho fazer a distinção entre indicadores, marcadores e estereótipos, como faz Labov (2008). 
Segundo Orsi (2008), a associação de um traço linguístico (p. ex.: diminutivo) com uma característica não linguística (p. ex.: sexo) constitui um estereótipo que permite inferir dados e realizar juízos de valor (p. ex.: falante feminina). Outro exemplo: traço linguístico (gíria), característica não linguística (idade) $=$ estereótipo (falante jovem).

\subsection{Tentando estabelecer os limites entre preconceito, estigma e estereótipo}

Os limites dos significados atribuídos a preconceito, a estigma e a estereótipo são às vezes tão estreitos - entrecruzando-se, intercruzando-se, imbricandose - que não é possível (nem necessário em alguns casos) determiná-los com exatidão. Frequentemente, esses termos são tomados como sinônimos. Calvet (2004), por exemplo, ao falar sobre preconceito, abre uma seção em seu livro que intitula Os preconceitos, chamando-os, na sequência, de estereótipos:

\section{Os preconceitos}

A história está repleta de provérbios ou de fórmulas pré-fabricadas que expressam os preconceitos de cada época contra as línguas. [...] Esses estereótipos não se referem a línguas diferentes apenas, mas também às variantes geográficas das línguas [...] (CALVET, 2004, p. 67 , grifos nossos).

Também Paiva e Soares (2009) misturam esses termos, mas, nesse caso específico, a confusão (se é que se pode chamar assim) se estabelece entre o uso sinonímico que se faz de preconceito e de estigma. Há, no texto das autoras, uma seção que, já pelo título, evidencia muito bem isso: Preconceito social, estigma linguístico: uma crença. A seção inicia-se assim:

Preconceito social, estigma linguístico: uma crença

$\mathrm{O}$ ato de repudiar aquilo que desconhece, ou que se apresenta como diferente do padrão é, muitas vezes, considerado como uma forma de preconceito [...]. 
Assim, o falar diferente que não obedece às regras da gramática normativa [...] está fadado ao preconceito social, por conseguinte, à estigmatização linguística. (PAIVA; SOARES, 2009, grifos nossos).

Em outro estudo, intitulado Bilinguismo e cultura, Faggion (2010), apresenta uma seção que chama de Estigma e estereótipo, mas que poderia perfeitamente ter recebido a denominação de Preconceito e estereótipo, pois a maneira como a autora faz referência a esses termos é sinônima:

O uso popular de tal estereótipo permite resumi-lo em uma só palavra: colono. [...] Não, não é um conceito típico de regiões de imigração. Outras áreas da sociedade brasileira estigmatizam o trabalhador rural de outras maneiras - caipira é uma das formas que mais ocorre. [...] O diferente, o outro, suscita riso e é ridicularizado. Não é a língua que é ridicularizada, mas a condição econômica de quem a fala. É o colono que sofre o preconceito, sua fala é apenas um dos elementos que o identificam. (FAGGION, 2010, grifos nossos).

Resumindo... Dentro dos estreitos limites existentes entre esses termos, parece haver algumas distinções possíveis:

(i) as noções de preconceito linguístico e de estigma têm, realmente, significados muito próximos, diferenciando-se, sobretudo, pela questão do grau da avaliação negativa: quanto mais negativa, quanto mais ligada à aversão, tanto mais próxima de estigma;

(ii) preconceito linguístico e estigma estão mais vinculados às atitudes linguísticas ${ }^{9}$, seja no sentido de produzi-las ou de recebê-las;

(iii) a depender do contexto ou dos objetivos do trabalho, preconceito e estigma podem ser usados como sinônimos ${ }^{10}$;

(iv) a noção de estereótipo sugere um vínculo mais estreito com as crenças linguísticas ${ }^{11}$, incluindo-se aí os conhecimentos e as emoções que determinado objeto linguístico pode suscitar;

${ }^{9}$ No sentido em que as tomamos neste trabalho, como componentes das crenças (a exemplo de López Morales).

${ }^{10}$ Como faz Faggion (2010, p. 109 e 112), no exemplo anteriormente dado.

${ }^{11}$ No sentido em que as tomamos neste trabalho, separando-as das atitudes. 
(v) estereótipo, embora esteja contextualmente vinculado a preconceito e a estigma, não possui o mesmo sentido deles e, portanto, não deve ser usado como forma sinônima.

\section{Considerações Finais}

Procurar entender o comportamento humano é procurar entender as ações realizadas pelos indivíduos em determinadas situações; tarefa nada fácil, já que os motivos que condicionam essas ações resultam da interação de diversos fatores, tais como personalidade, cultura, experiências pessoais, dentre outros.

Realizar estudos que incluem reflexões concomitantes da Sociolinguística e de Crenças e Atitudes Linguísticas pode propiciar a compreensão mais adequada das ações que guiam o comportamento dos indivíduos em relação à sua fala e à fala do(s) outro(s), bem como os motivos, internos ou externos à língua, que condicionam tais ações. Pode, também, contribuir para ampliar a discussão sobre os desdobramentos desses estudos, tais como: os fatores de mudanças e de manutenção linguísticas de dialetos, a influência sobre o aprendizado de segundas línguas, as questões de prestígio e desprestígio (que levam ao preconceito não só em relação à língua que o outro fala, mas também em relação à comunidade desses falantes, o que pode contribuir para a desvalorização de variedades dialetais e, por extensão, de marcas identitárias) e a manutenção do discurso monolíngue em nosso país.

\section{Referências}

AGUILERA, V. de A. Crenças e atitudes lingüísticas: quem fala a língua brasileira? In: RONCARATI, C.; ABRAÇADO, J. (Orgs.). Português brasileiro II: contato lingüístico, heterogeneidade e história. Niterói: Editora Federal Fluminense, 2008. p. 311-333.

APPEL, R.; MUYSKEN, P. Bilingüismo y contacto de lenguas. Barcelona: Ariel, 1996. 
BARCELOS, A. M. F. Reflexões acerca da mudança de crenças sobre ensino e aprendizagem de línguas. Revista Brasileira de Linguística Aplicada, Belo Horizonte, v. 7, n. 2, p. 109-138, 2007.

BERGAMASCHI, M. C. Z. Bilingüismo de dialeto italiano-português: atitudes lingüísticas. 2006. Dissertação (Mestrado em Linguística) - Universidade de Caxias do Sul, Caxias do Sul.

BISINOTO, L. S. J. Atitudes sociolingüisticas: efeitos do processo migratório. Campinas: Pontes, 2007.

BORBA, F. da S. Dicionário Unesp do português contemporâneo. São Paulo: Editora Unesp, 2004.

CALVET, J.-L. Sociolingüística - uma introdução crítica. Tradução Marcos Marcionilo. São Paulo: Parábola, 2004.

CAMARA JR., J. M. História da Lingüística. Tradução Maria do Amparo Barbosa de Azevedo. Petrópolis: Vozes, 1975.

FAGGION, C. M. Bilinguismo e cultura. In: FROSI, V. M.; FAGGION, C. M.; DAL CORNO, G. O. M. Estigma: cultura e atitudes linguísticas. Caxias do Sul: EDUCS, 2010. p. 99-119.

FÉLIX, A. Crenças do professor sobre o melhor aprender de uma lingua estrangeira na escola. 1998. Dissertação (Mestrado em Linguística Aplicada) Universidade Estadual de Campinas, Campinas.

FERREIRA, A. B. de H. Novo dicionário eletrônico Aurélio. 4. ed. Curitiba: Positivo, 2009. 1 CD-Rom.

FROSI, V. M.; FAGGION, C. M.; DAL CORNO, G. O. M. Da estigmatização à solidariedade: atitudes linguísticas na RCI. In: FROSI, V. M.; FAGGION, C. M.; DAL CORNO, G. O. M. Estigma: cultura e atitudes linguísticas. Caxias do Sul: EDUCS, 2010. p. 15-42.

GILES, H.; RYAN, E. B.; SEBASTIAN, R. J. An integrative perspective for the study of attitudes toward language variation. In: GILES, H.; RYAN, E. B. (Eds.). Attitudes towards language variation: social and applied context. London: Edward Arnold, 1982. p. 1-19. 
GOFFMAN, E. Estigma: notas sobre a manipulação da identidade deteriorada. 4. ed. Rio de Janeiro: Guanabara, 1988.

HELENE, A. F; XAVIER, G. F. Como as memórias criam a personalidade. 10 mar. 2004. Disponível em <http://migre.me/qF1sQ>. Acesso em: 9 set. 2012.

HOUAISS, A. Dicionário Honaiss da lingua portuguesa. Rio de Janeiro: Objetiva, 2009.

LABOV, W. Padrões sociolingüisticos. São Paulo: Parábola, 2008 [1972].

LAMBERT, W. E. A Social Psychology of Bilingualism. In: PAULSTON, C. B.; TUCKER, G. R. (Orgs.). Sociolinguistics: the essential readings. Malden, MA: Blackwell Publishing, 2003 [1967].

LAMBERT, W. W.; LAMBERT, W. E. Psicologia social. 3. ed. Rio de Janeiro: Zahar, 1972.

LÓPEZ MORALES, H. Sociolingü̈stica. $3^{\text {a }}$ ed. Madrid: Gredos, 2004. MORENO FERNÁNDEZ, F. Principios de sociolingüistica y sociología del linguaje. Barcelona: Ariel, 1998.

NASCENTES, A. Dicionário de sinônimos. 3. ed. Rio de Janeiro: Nova Fronteira, 1981.

ORSI, L. Estereotipos y actitudes: similitudes y diferencias. In: CONGRESSO INTERNACIONAL DA ALFAL, 15., 2008, Montevidéu. Anais... Montevidéu: ALFAL, 2008. Disponível em: <http://migre.me/qF22D>. Acesso em: 11 ago. 2012. p. 1-11.

PAIVA, G. M. F.; SOARES, M. E. Preconceito e identidade linguística: crenças de estudantes de curso de educação à distância. In: ENCONTRO NACIONAL SOBRE HIPERTEXTO, 3., 2009, Belo Horizonte. Anais... Belo Horizonte: Centro Federal de Educação Tecnológica de Minas Gerais, 2009. Disponível em: <http://migre.me/qF25p>. Acesso em: 15 set. 2011. p. 1-12. 
RODRIGUES, A. Psicologia social. 2. ed. Petrópolis: Vozes, 1972.

SILVA, A. K. da. Crenças e aglomerados de crenças de alunos ingressantes em Letras (inglês). 2005. Dissertação (Mestrado em Linguística Aplicada) Universidade Estadual de Campinas, Campinas.

SILVA, A. K. da. Crenças no ensino-aprendizagem e na formação de professores de línguas: pontos e contrapontos. In: SILVA, K. A. (Org.). Crenças, discursos \& linguagem. v. II. Campinas: Pontes, 2011. (no prelo).

SILVA, T. T. A produção social da identidade e da diferença. In: SILVA, T. T. (Org.). Identidade e diferença: a perspectiva dos estudos culturais. Petrópolis: Vozes, 2000. p. 73-102.

UFLACKER, C. M.; SCHNEIDER, M. N. Atitudes lingüísticas e variedades dialetais alemãs. Revista Uniletras, Ponta Grossa, v. 30, n. 1, p. 33-51, ja./jun. 2008.

WOODWARD, K. Identidade e diferença: uma introdução teórica e conceitual. Tradução Tomaz Tadeu da Silva. In: SILVA, T. T. (Org.). Identidade e diferença: a perspectiva dos estudos culturais. Petrópolis: Vozes, 2000. p. 7-72.

YERO, J. L. Teaching in mind: how teacher thinking shapes education. $2^{\text {nd }}$ ed. Hamilton, MT: Mind Flight Publishing, 2010.

Recebido em: 19/11/2014

Aceito: 03/04/2015 